\title{
Preparation of Nano-silica Fume Coating Rubber Composite Particle and Its Application in Toughening the Oil Well Cement Stone
}

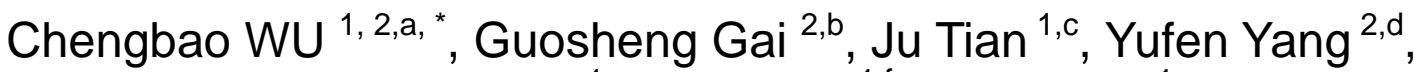 \\ Chuansheng Liu ${ }^{1, \mathrm{e}}$, Lei Kong ${ }^{1, \mathrm{f}}$, Jian Wang ${ }^{1, \mathrm{~g}}$
}

\author{
${ }^{1}$ School of Aircraft Maintenance Engineering, Guangzhou Civil Aviation College, Guangzhou \\ 510470, P.R. China \\ ${ }^{2}$ School of Materials Science and Technology, Tsinghua University, Beijing 10084, P.R. China \\ awuchengbao@126.com, bgaigs@mail.tsinghua.edu.cn, ctianju@caac.net, dyangyufen@mail.tsingh \\ ua.edu.cn, ${ }^{\mathrm{e}}$ liuchuansheng@caac.net, ${ }^{\mathrm{f}}$ konglei@caac.net, ${ }^{9}$ wangjian@caac.net, "corresponding \\ author
}

Keywords: Nano-silica fume; Rubber particle; Composite particles; Oil well cement stone; Toughening

\begin{abstract}
A kind of nano-silica fume coating rubber composite particles was prepared by the Particle Composite System (PCS), and the adhesion performance of composite particles was tested by the high-speed agitating test, the composite particles were filled into the oil well cement slurry to toughen the oil well cement stone. The results indicated that the surface of the rubber particles is coated with nano-silica layer, and the composite particles are grey; the adhesion between the silica fume and the rubber particles is good; the elastic modulus of oil well cement stone reduces by $20 \%$ and the Possion ratio increases by $5.1 \%$ as the filler fraction is $4 \mathrm{wt} . \%$. Therefore, the nano-silica fume coating rubber composite particles can improve the toughness of oil well cement stone.
\end{abstract}

\section{Introduction}

The tough materials including fiber [1][2], latex particles [3], rubber particles [4] and organic resin [5] are used in the oil well cement slurry to improve the toughness and cementation performance of oil well cement stone. The latex particles and organic resin materials are limited use for their high price, the rubber particles and silica fume are widely used in toughening the oil well cement stone for the low price and wide resource. But, the density of the silica fume is heavier than that of the oil well cement; otherwise, the density of the rubber particle is much lighter than that of the oil well cement. Therefore, the rubber particles and silica fume cannot mix with oil well cement slurry evenly. To resolve the problem, the nano-silica fume is coated orderly on the surface of the rubber particles by the PCS, and the nano-silica coating rubber composite particles are prepared. The density of the nano-silica coating rubber composite particles reduces the density difference in the slurry and can be dispersed orderly, so as to improve the stability of cement slurry.

\section{Experimental}

Particles Composite System. High speed pneumatic impact particle composite technology is widely researched in all over the world [6-11]. In china, the Powder Engineering Laboratory of Materials Science and Technology of Tsinghua University is the first research institution which developed the high speed pneumatic impact PCS [12]. Now, the PCS is widely used to prepare the composite particles and finish the shape of the powder.

The components of PCS include the main mechanic, the catcher and control system. The nano-silica fume and rubber particles mixed evenly are fed into the main mechanic by the quantitative metering system. The main mechanic includes rotors, stators and the loop, as the Fig. 1 shows: 


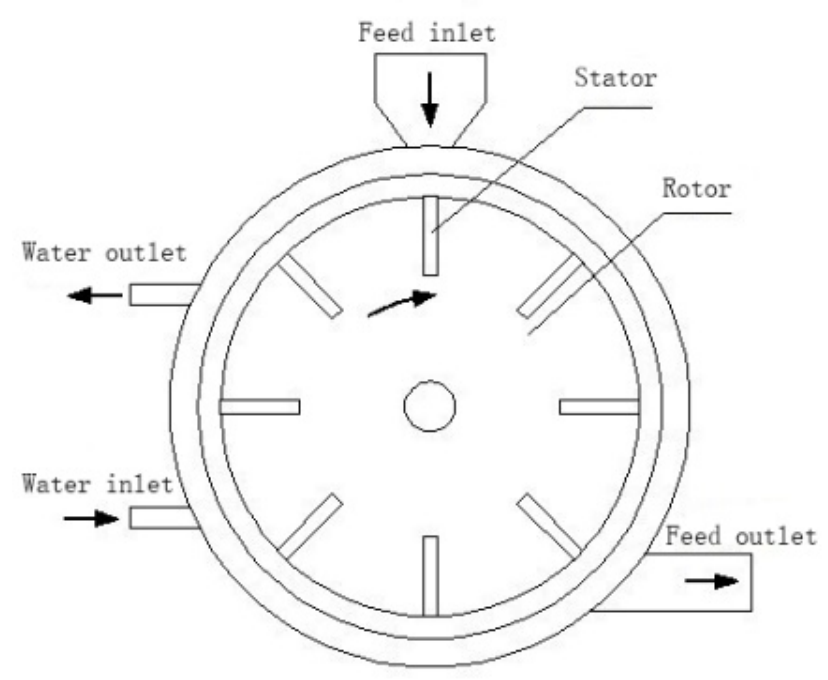

Fig.1 Schematic diagram of the main mechanic of PCS

The particle materials are dispersed by the components of the main mechanic. At the same time, the strong impact force, compressive force, frictional force and shear force among the particles can coat the small particles on the surface of the big particles or mix different particles evenly in a short time.

Composite Technic of Micron-Nano-Sized Particles Composite system. The rubber particles and the silica fume nano-sized particles with a certain proportion are fed into the PCS. The experimental parameters are adjusted, and the two kinds of particles are contacted and mixed fully to form a core-shell structure, silica fume coating rubber composite particle. The process flow as Fig.2 shows:

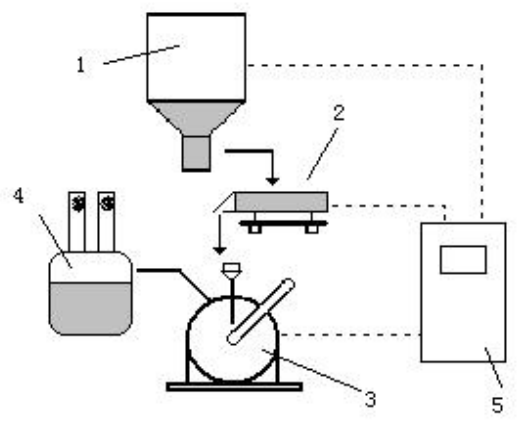

1.OM mixer 2.quantitative metering system 3. PCS main mechanic 4. collecting device 5. control system

Fig. 2 the process flow of PCS

Experiment of Nano-Silica Fume Coating Rubber Particle. The nano-silica fume, with diameter range from $70 \mathrm{~nm}$ to $500 \mathrm{~nm}$, was provided by the Elkem ASA Corporate Headquarters (Tianjin, China), the rubber particles were provided by the Dongguan Liyuan Rubber Products Co., LTD (Dongguan, China). The nano-silica could be coated on the surface of rubber particle orderly after being disposed by the PCS. Thus, the properties of oil well cement can be improved at the low filler content. The experimental parameters are as the table 1 show:

Table 1 Experimental parameters for nano-silica fume coating the rubber particles

\begin{tabular}{llll}
\hline $\begin{array}{l}\text { Weight of rubber } \\
\text { particles }(\mathrm{Kg})\end{array}$ & $\begin{array}{l}\text { The content of } \\
\text { nano-silica fume (\%) }\end{array}$ & \multicolumn{2}{l}{ The experimental parameters of PCS } \\
\cline { 3 - 4 } & 5 & $\begin{array}{l}\text { Rotor rotational } \\
\text { speed(rpm) }\end{array}$ & $\begin{array}{l}\text { Processing } \\
\text { time(min) }\end{array}$ \\
\hline 1 & 10 & 2500 & 30 \\
1 & 2500 & 30 \\
\hline
\end{tabular}




\section{Results and Discussion}

SEM of Nano-Silica Fume Coating Rubber Composite particles. The SEMs of nano-silica fume coating rubber composite particles were show in Fig.3 and Fig.4. The Fig.3 showed the composite particles with the content of nano-silica fume 5wt.\%, the composite particles with the content of nano-silica fume 10wt.\% was shown in Fig.4.

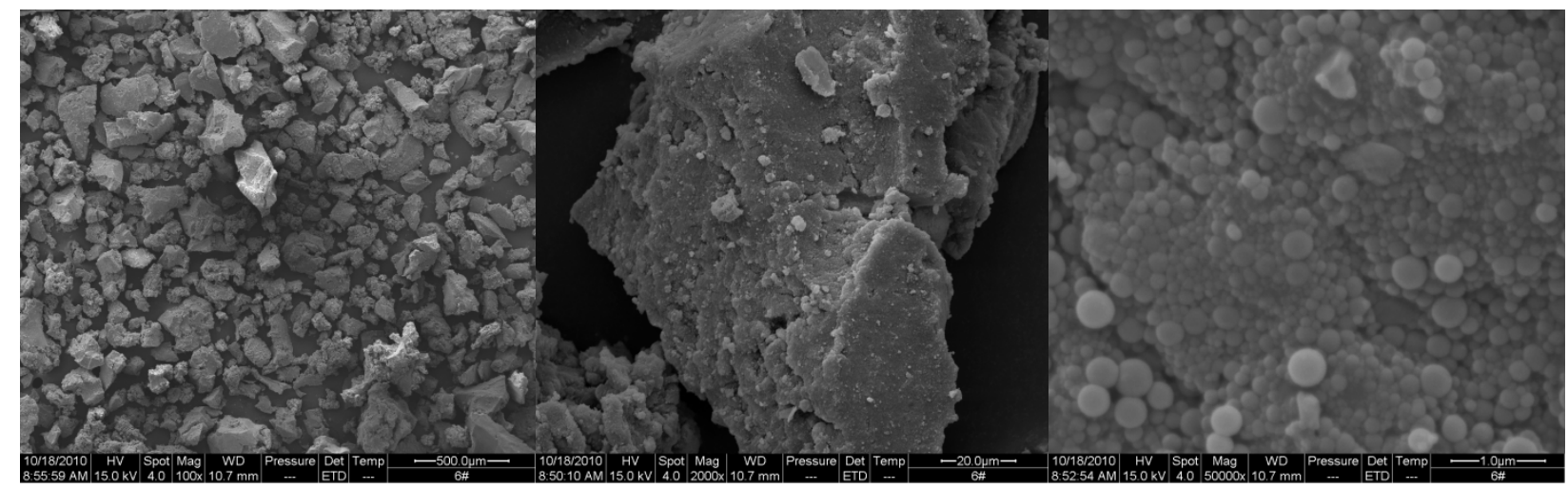

(a)

(b)

(c)

(a) $100 \times$ (b) $2000 \times$ (c) $50000 \times$

Fig.3 the SEMs of the composite particles with the content of nano-silica fume 5wt.\%

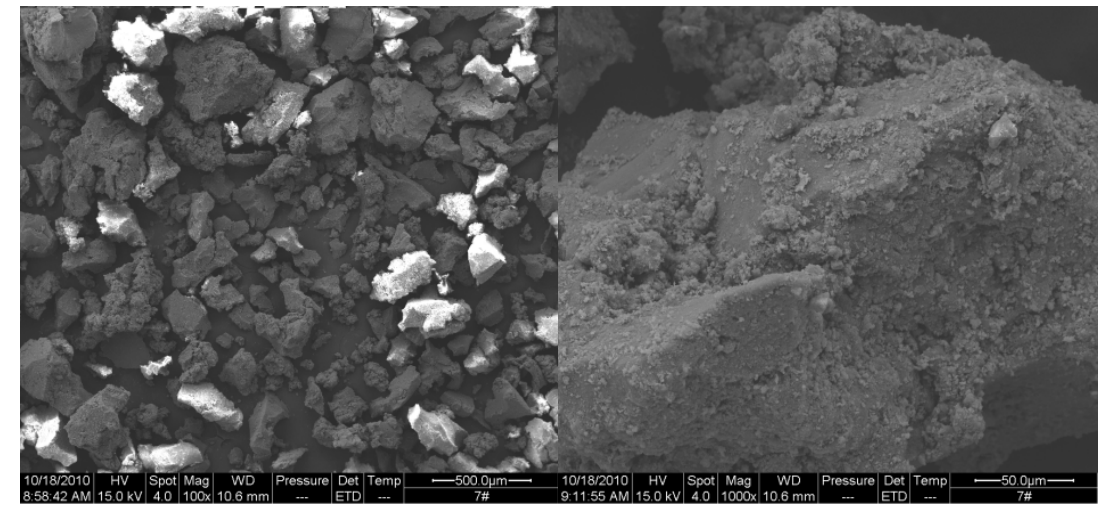

(a) (b)

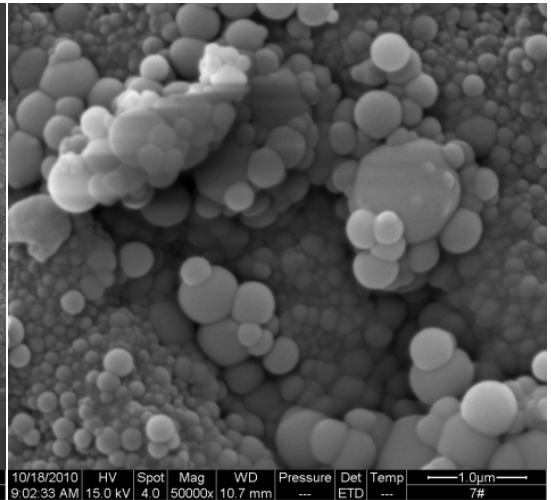

(c)

(a) $100 \times$ (b) $1000 \times$ (c) $50000 \times$

Fig. 4 the SEMs of the composite particles with the content of nano-silica fume 10wt.\%

It can be seen from Fig.3 that the nano-silica fume can not be found on the surface of the rubber particle at the relatively small manification100 (Fig.3(a)), and the surface of the composite particle is black; when the magnification was 2000 (Fig.3(b)), the silica fume can be seen on the surface of the rubber particle, and surface of the composite particle is black gray, when the magnification is 50000 (Fig.3(c)), one can see the nano-size spherical silica particles connect together, and the surface is the light black gray. We can see from Fig.4 that the nano-silica fume cannot be found on the surface of the rubber particle at the relatively small manification100 (Fig.4(a)) also, and the surface of the composite particle is black; when the magnification is 1000 (Fig.4(b)), the silica fume can be seen on the surface of the rubber particle, and surface of the composite particle is off-white; when the magnification is 50000 (Fig.4(c)), the nano-size spherical silica particles connecting together can be seen, and the surface of the composite particle is light off-white. by analyzing the Fig. 3 and Fig. 4 comparatively, we can find that the composite particles with the content of nano-silica fume $10 \mathrm{wt} . \%$ is whiter than those with the content of nano-silica fume $5 \mathrm{wt} . \%$.

The Check on the Adhesion Property of the Composite Particles. The composite particles with the content of the nano-silica fume $5 \mathrm{wt}$.\% were agitated at high speed. Then, one small amount of composite particles after agitation were observed by SEM, the SEM image is shown in Fig.5; another small amount of composite particles were maintained at the atmospheric pressure and with 
the temperature $95^{\circ} \mathrm{C}$, and then observed by SEM, the SEM image is shown in Fig.6.

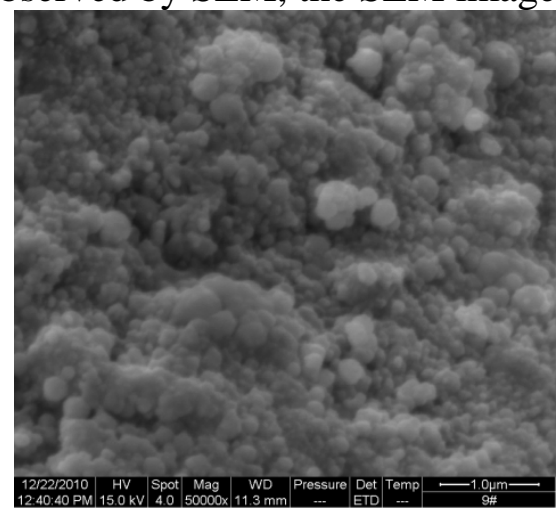

Fig.5 SEM of composite particles after high speed agitating test

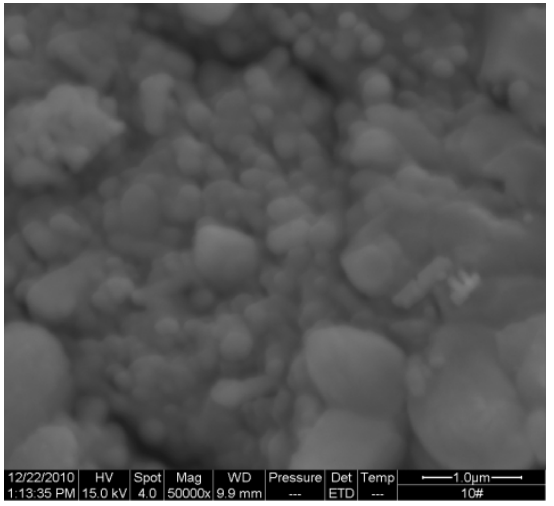

Fig.6 SEM of composite particles after high speed agitating test and maintenance at the temperature $95^{\circ} \mathrm{C}$

From Fig.5 and 6, we can estimate that adhesion between the nano-silica particles and the rubber particles is good. that is, the nano-silica particles do not come off the rubber particles.

Evaluation Test for Composite Particles Toughening the Oil Well Cement. The comprehensive mechanical properties of oil well cement filled with nano-silica fume coating rubber composite particles are show in Table 2.

Table 2 Comprehensive mechanical properties of oil well cement filled with composite particles

\begin{tabular}{cccc}
\hline $\begin{array}{c}\text { The filling fraction of the composite } \\
\text { particles }\end{array}$ & $\begin{array}{c}\text { Possion } \\
\text { ratio }\end{array}$ & $\begin{array}{c}\text { Elastic } \\
\text { modulus }\end{array}$ & $\begin{array}{c}\text { Compressive } \\
\text { strength }\end{array}$ \\
\hline $4 \mathrm{wt} \%$ & 0.41 & $13.8 \mathrm{GPa}$ & $23 \mathrm{MPa}$ \\
0wt.\% & 0.39 & $17.3 \mathrm{GPa}$ & $31 \mathrm{MPa}$ \\
Results comparison & $+5.1 \%$ & $-20.2 \%$ & $-25.8 \%$ \\
\hline
\end{tabular}

It can be seen from Table 2 that the passion ratio of the oil well cement stone increases to 0.41 after being filled with 4 wt.\%, 5.1\% increased; the elastic modulus decreased from 17.3GPa to 13.8GPa, 20.2\% decreased. That is to say, the composite particles can toughen the oil well cement stone.

\section{Conclusions}

A new kind of composite particles were prepared in this work, and the adhesion performance of composite particles was tested. At last, the composite particles were filled into the oil well cement slurry to toughen the oil well cement. The following conclusions were gained that the nano-silica fume are coating on the surface of the rubber particle, and the composite particles are grey; the adhesion between the silica fume and the rubber is good; the toughness of oil well cement stone is improved by filling the nano-silica fume coating rubber particles. 


\section{References}

[1] M. LI, M. Liu, Y. Yang, Z.Y. LI, X. Guo. Mechanical properties of oil well cement stone reinforced with hybrid fiber of calcium carbonate whisker and carbon fiber[J]. Petroleum Exploration and Development Online, 42 (2015) 104-111.

[2] M. Li, S. Zhou, X.Y. Guo. Effects of alkali-treated bamboo fibers on the morphology and mechanical properties of oil well cement[J]. Construction and Building Materials, 150(2017)619-625.

[3] Z.C. Lu, X.M. Kong, Q. Zhang, etc. Influences of styrene-acrylate latexes on cement hydration in oil well cement system at different temperatures[J]. Colloids and Surfaces A: Physicochemical and Engineering Aspects, 507(2016)46-57.

[4] X.W. Cheng, S. Huang, X.Y. Guo, W.H. Duan. Crumb waste tire rubber surface modification by plasma polymerization of ethanol and its application on oil-well cement[J]. Applied Surface Science, 409(2017)325-342.

[5] Z.Q. Zhang, P.Y. Yan. Hydration kinetics of the epoxy resin-modified cement at different temperatures[J]. Construction and Building Materials, 150(2017)287-294.

[6] T. Isao, M. Koishi, K. Shinohara. A study on the process for formation of spherical cement through an examination of the changes of powder properties and electrical charges of the cement and its constituent materials during surface modification[J]. Cement and Concrete Research, (2002)57-64.

[7] H. Kenji. Particle surface modification on dry method[J]. Powder Science and Engineering, 34(2002)77-83.

[8] X.G. Li, S. Takahashi, K. Watanabe et al. Fabrication and characteristics of $\mathrm{Fe}_{3} \mathrm{O}_{4}$-polymer composite particles by hybridization[J]. Powder Technology, 133(2003)156-163.

[9] T. Isao, K. Masumi. Fundamental properties of powder, paste and mortar of surface modified cement and process of the surface modification[J]. Construction and Building Materials, 13(1999)285-292.

[10] A. Masanobu, T. Yasumasa, K. Yoshitaka. Microstructure control of an oxide superconductor by a hybridization process through grinding[J]. Solid State Tonics, 101-103(1997)111-117.

[11] R. Pfeffer, R.N. Dave, D.G. Wei et al. Synthesis of engineered particulates with tailored properties using dry particle coating[J]. Powder Technology, 117(2001)40-67.

[12] F.X. Wang, G.S. Gai, C.C. Jia. Fabrication of $\mathrm{Al}_{2} \mathrm{O}_{3} / \mathrm{Cu}$ composite particles by MA \& PCS[J]. The 4th China International Conference on High-Performance Ceramics.2005 